\title{
Influence of the annealing time on the structural properties for Flash evaporated InSb films
}

\author{
A.K.M.Al-Bderi*
}

Ms. M.J.K.Alagaly**

Date of acceptance 2/4/2007

\begin{abstract}
:
Indium Antimonide ( $\mathrm{InSb}$ ) thin films were grown onto well cleaned glass substrates at substrate temperatures $(473 \mathrm{~K})$ by flash evaporation. X-ray diffraction studies confirm the polycrystalline of the films and the films show preferential orientation along the (111) plane .The particle size increases with the increase of annealing time .The transmission spectra of prepared samples were found to be in the range $\left(400-5000 \mathrm{~cm}^{-1}\right)$ from FTIR study. This indicates that the crystallinity is improved in the films deposited at higher annealing time.
\end{abstract}

\section{Introduction}

Indium Antimonide ( $\mathrm{InSb})$ is a binary III-V compound with the highest mobility carriers at room temperature, and thus it is the best material available for magnetic-field sensing devices such as Hall sensors and magneto resistors[1], speed - sensitive sensors [2], millimeter wave devices [3] and magnetic sensors [4]. Many reports are available on the growth of $\mathrm{InSb}$ thin films using techniques such as molecular beam epitaxy (MBE) [5],metal organic chemical vapor deposition (MOCVD) [6] and vacuum evaporation [7]. Of all the methods used to prepare InSb films, vacuum evaporation is the very simple and inexpensive technique and can be used for large area deposition [8]. The problem of non-stoichiometry could also be addressed properly by optimizing the conditions of evaporation. The present article explains the effect of annealing time on the structural and optical properties of InSb thin films by flash evaporation.

\section{Experimental work and procedure}

\subsection{InSb Compound And Film Preparing}

InSb Polycrystalline alloy have been prepared by mixing of In and $\mathrm{Sb}$

high purity (99.999\%) in quartz tube evacuated at pressure of $\left(10^{-5}\right.$ mbar $)$. The tube was sealed and heated in a furnace type Mimert. The temperature was kept at $\left(973 \mathrm{~K}^{\circ}\right)$ for $(4 \mathrm{~h})$. The tube were continuously rotated and rocked during the reaction to insure homogeneity. Then the temperature be reduced to $803 \mathrm{~K}$ for (5h) according to the phase diagram Fig (1) [9] then quenched by cold water .The flash evaporated $\mathrm{InSb}$ films, were prepared by using Edward's coatings unit model E306A This technique was first described by Siegel and Harris [10]. It has been used in the evaporation and epitaxy of Barium Titanate. The same technique was used to prepare of InSb films as shown schematically in Fig. (2). The evaporate, crushed into fine grains as InSb powder by using glass pestle, this powder is continuously dropped into a heated boat by vibrating hand made system. The powder drops from the feed through (chute)passing through a tantalum guide funnel into the input opening of a covered high temperature Molybdenum box source, resistively heating to about $1573 \mathrm{~K}$, by reading of the calibrated oven thermocouple. And were prepared (Al) electrodes by thermal evaporation .All these systems work with combination of rotary and diffusion vacuum to give an

*As. lectu.,Coll.of Sci.Unv.of Wasit

**As. Physist,Coll.of Sci.Unv.of Wasit 
ultimate vacuum pressure of about $1-2 \times 10^{-5}$ mbar. The vacuum pressure was monitored by pirani and penning gauges Edward type.

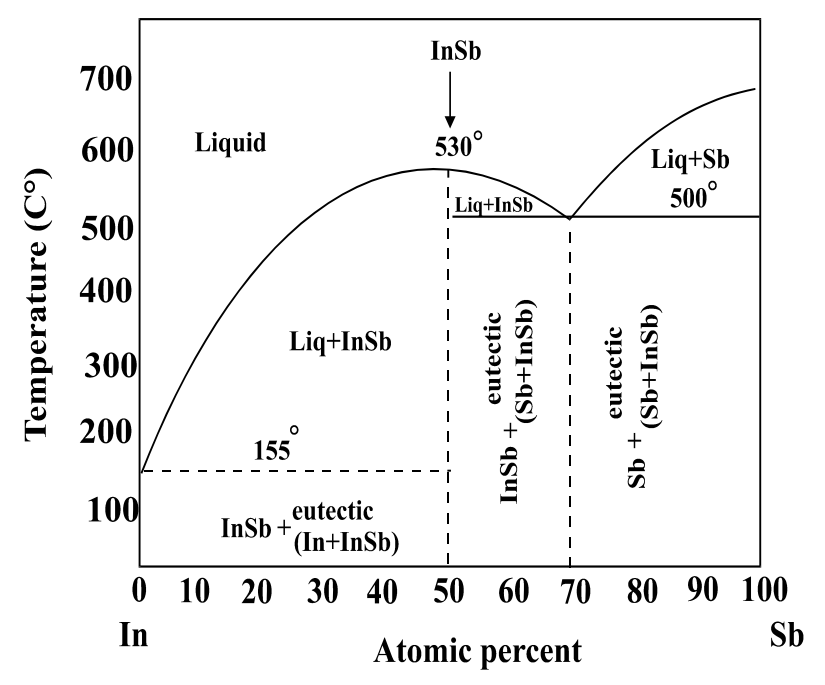

Fig (1) phase diagram for InSb[9]

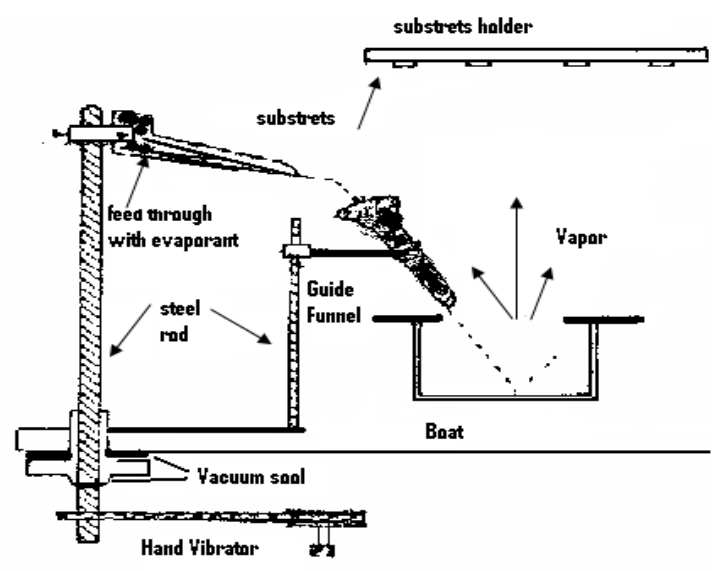

Fig (2) Apparatus for Flash deposition[10]

\section{Result \& Discussion}

\subsection{Structural Analysis}

a)X-ray Diffraction Analysis

The X-ray diffraction (XRD) investigation have been carried out for the prepared alloys powder of InSb compound. The results are illustrated in Fig (1) .According to (ASTM) cards, the structure and exhibited cubic strictures a cording to miller indices.

The XRD patterns of InSb films as deposited and annealed at (473) $\mathrm{K}$ for (20, 40, 60 and 80)mints and prepared by flash evaporation are presented in figure
(3). Fig. (3) indicate to exist of a polycrystalline film. At $\mathrm{T}_{\mathrm{i}}$ : 20 mints the XRD analysis exhibits two characters diffraction peak appeared corresponding to the (111), and (220) reflection of polycrystalline InSb films. This structure is agreement with previous work on III- V compounds [7] . For $\mathrm{T}_{\mathrm{i}}: 40$ and 60 mints we can see the same peaks and in the same position, but can see the increase of intensity of peaks respectively for (111) and (220) reflection of polycrystalline InSb films. This due to the phase transition from polycrystalline to crystalline structure increase of degree of crystallnity. At $\mathrm{T}_{\mathrm{i}}: 80$ mints the XRD patterns is exhibited two peaks at (111) and (220) This effect may be attributed to the nucleation and growth of the grain size due to the annealing process. This gives rise to that the heat treatment of these films minimized some of their defects, since the annealing process usually affects the structure of the films. The results are in comparable with films prepared by other techniques[7,12] .It is concluded that the polycrystalline $\mathrm{InSb}$ films can be grown highly oriented along the (111)direction by flash evaporation technique .

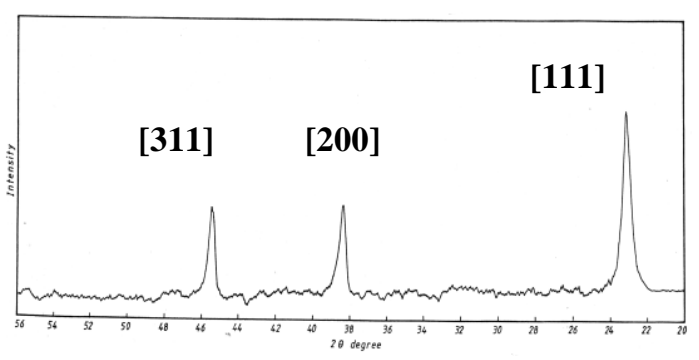

Fig. (3) XRD Pattern of InSb Alloy

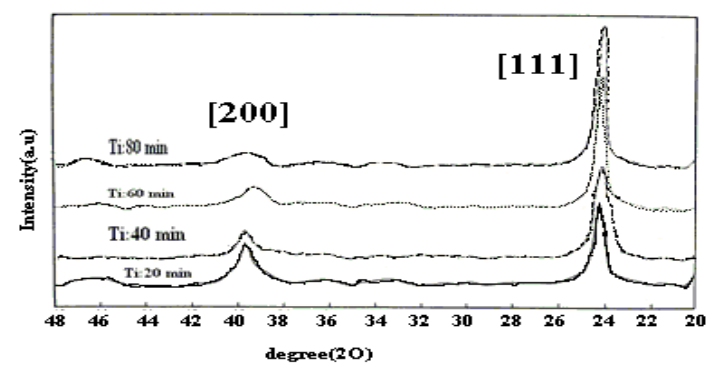

Fig. (4) XRD Pattern of InSb Films prepared by Flash evaporation 


\subsection{FT-IR Transmission Spectra of InSb Films}

Fig (5) show the FTIR spectrum of samples prepared by flash evaporation and different time annealing $\mathrm{Ti}$, the transmission spectra exhibited peak at $1232.01,1273.71,1297.2$ and $1168.3 \mathrm{~cm}^{-1}$ at $\mathrm{T}_{\mathrm{i}}: 20,40,60,80$ mints respectively and these are called band gap values .The band gap calculated from the infrared transmission spectrum(i.e. from fitting of the absorption edge) were dislocation [12] and also the prepared films contained some excessive defects [13] the FT -IR transmission not detected any In-In bond in the InSb samples.

\section{Conclusion:}

In summary, all InSb films examined in this study exhibited

Polycrystalline behavior and cubic strictures. the band gap value of InSb thin films increases as the annealing time increases. but at 80 mints we can see

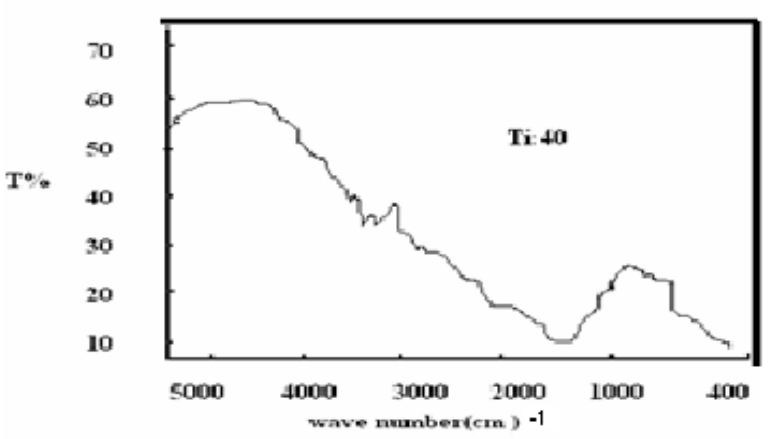

(b)

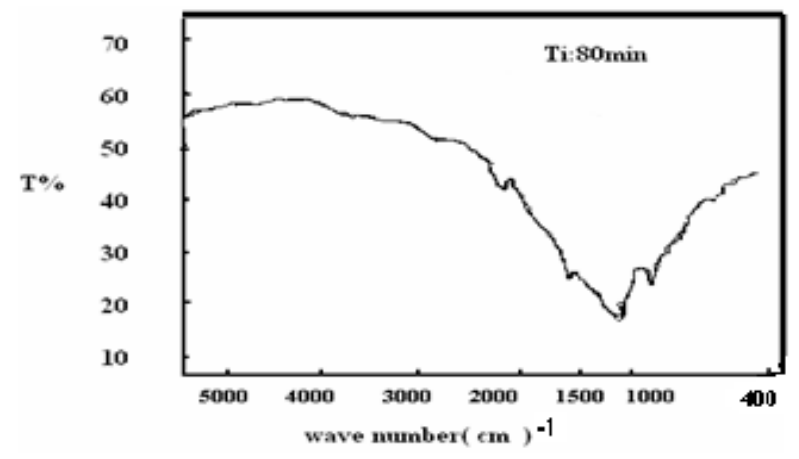

(d)

(c)

Fig. (5) FT-IR Transmission for InSb Films

(a) $\mathrm{T}_{\mathrm{i}}: 20 \mathrm{~min}, \quad$ (b) $\mathrm{T}_{\mathrm{i}}: 40 \mathrm{~min}, \quad$ (c) $\mathrm{T}_{\mathrm{i}}: 60 \mathrm{~min}$, (d) $\mathrm{T}_{\mathrm{i}}: 80 \mathrm{~min}$

$, 0.152,0.167,0.161$ and $0.145 \mathrm{eV}$ for the $\mathrm{InSb}$ thin films deposited at $\mathrm{Ti}$ equal 20,40,60, and 80 mints and temperature $473 \mathrm{~K}$. it is found that the band gap value of InSb thin films increases as the annealing time increases [12] . but at 80 mints we can see decreases energy gap which may be due to high density of decreases energy gap which may be due to high density of dislocation and also the prepared films contained some excessive defects. 


\section{References:}

1. Heremans, J., Partin, D.L., and Thrush,C. M.1993. Effect of an $\operatorname{In}_{1-\mathrm{x}} \mathrm{Al}_{\mathrm{x}}$ $\mathrm{Sb}$ buffer layer on $\mathrm{InSb}$ thin film mobility. Semicond. Sci. Technol. 8: 5424-5428.

2. Carpenter, M. K. and Verbrugge, M. W. 1994. preparation and Characterization of vacuum evaporated InSb thin films, J. Mater. Res. 9:25842586.

3. Thundat T., Mahapatra S.M., Dev B.N.,Gibson W.M. and Das T.P.1988. Experimental and theoretical investigations of Chemisorbed $\mathrm{InSb}$ on Si (111), J.Vac. Sci. Technol. A6: 681683

4. Okamoto, A., Ashihara, A., Akaogi T., and Shibasaki, I. 2001 .InSb Thin Films grown on GaAs Substrate and their Magneto- Resistance Effect, J. Crystal. Growth, 227: 619-624.

5. Shibasaki, I., Okamoto, A., Ashihara,A., and Suzuki, K.2001.Properties and Applications of InSb Single Crystal Thin Film Hall Elements, Technical Digest of the $18^{\text {th }}$ Sensor Symposium.6: 233-238.

6.Gaskill, D. K., Stauf, G. T., and Bottka, N. 1991.Characterization of MOCVD a InSb film on a GaAs(111) substrate, Appl. Phys.Lett. 58:1905-1916.

7. Senthilkumar, V., Venkatachalam, S., Viswanathan, C., Gopa, S.2005.Influence of substrate temperature on the properties of vacuum evaporated InSb films ,Cryst. Res. Technol. 40(6):573 - 578.

8. Singh, J., Semiconductor Devices Basic Principles. 2001. New York, Wiley, 1: 313-327.

9. Lida, Shosan, 1989.Thermal and structural properties of InSb thin Film, J.Appl. Phys. 65(5): 1977-1980.

10. Kruse, Paul W.1970. Semiconductors and semimetals. Ed. Willardson, R.K. and Beer, A.C., Academic press, New York, 2:46-47.

11. Tolansky, S. 1948. Multiple Beam Interferometer of Surfaces and Films, Oxford University Press. Oxford. 1:125.

12. Dixit, V. K., Rodrigues, B. V., Bhat H. L., Venkataraghavan, R., Chandrasekaran K. S., and Arora B. M. 2002. Growth of InSb epitaxial layers on GaAs (001) substrates by LPE and Their characterizations, J.Cryst.Growth 235: 154-156.

13. Gadkari, D. B., Lal, K. B., and Arora, B. M. 1998. Crystal growth, spectral and thermal properties of nonlinear optical Crystal InSb, Bull. Mater. Sci., 21 (2):127-132 .

\section{تأثير زمن التَلْدين على الخصائص التركيبية لأغثيةِ InSb المحضرة بطريقة التبخير ألوميضي}

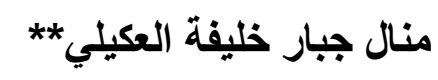

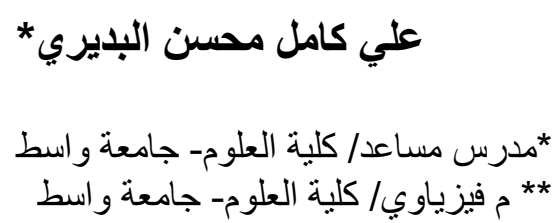

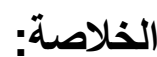

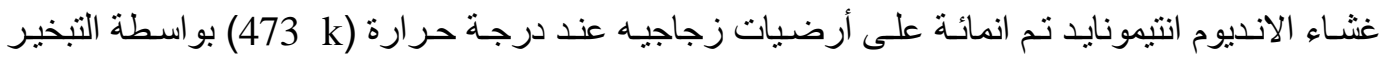

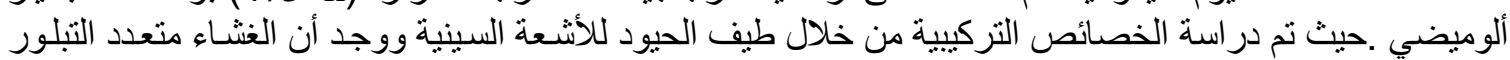

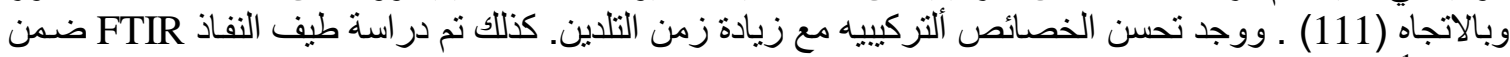
الددى 